\title{
Öğretmenlerin Yöneticilerden Memnuniyet Düzeylerinin İş Performanslarına Etkisi
}

\section{The Impact of Teacher Satisfaction Levels from Managers on Business Performance}

\begin{abstract}
Nursel YARDİBं*
Öz: Örgütlerin performansı örgütün önceden belirlenen hedeflerini gerçekleştirme sürecinde etkili olduğu kadar öngörülemeyen krizleri sağ lkklı yönetme konusunda da etkilidir. Bu çalışmada öğretmenlerin okul yöneticilerinden memnuniyet düzeylerinin iş performanslarına etkileri ile ilgili görüşlerini ortaya koymak amaçlanmıştır. Çalışmada araştırma yöntemi olarak nitel araştırma desenlerinden durum çalışması tercih edilmiştir. Çalışma grubu 2016-2017 eğitim-öğretim yılında Ankara ilinde ilkokullarda derse giren 10 kadın, 10 erkek toplam 20 sınıf öğretmeninden oluşmaktadır. Öğretmenlerin çalışmaya katılmaları gönüllük esasına dayanmaktadır. Öğretmenlerin mesleki kıdemleri ise 3 yıl ile 20 yıl arasında farklılık göstermektedir. Çalışmada katılımcıların yarısından çoğu yöneticilerin yönetici yeterliliklerine sahip olduğunu düşünürken bazı katılımcılar ise yeterliliğe sahip olmadığını düşünmektedirler. Katılımcılar yöneticilerin insan ilişkilerine önem verdiğini, yöneticilerin öğretmenleri değerlendirirken kullandığı kriterleri duyurduklarını, ifade etmişlerdir. Katılımcıların yarısından çoğu yöneticilerin öğretmenlerin problemlerine duyarlı olduğu konusunda görüş birliği içerisindedir. Çalışmada katılımcılar yöneticilerden memnuniyetin iş performansını etkilediğini ifade etmişlerdir. Öğretmenlerin yöneticilerden memnuniyet durumunun iş performansına etkisinin öğretmenlerin cinsiyetine ve mesleki kıdemlerine göre bir farklılık göstermediği belirlenmiştir. Özellikle okul ortamında öğretmenlerin motivasyonunun arttırılması ve performanslarının değerlendirilmesi konularında yöneticilere hizmet içi eğitim verilebilir. Öğretmenlerin takdir, tanıma ve ödüllendirme konularında memnuniyetini artırmak adına ödüllendirme sisteminde yapısal değişiklikler yapılabilir.
\end{abstract}

Anahtar Kelimeler: İş performansı, memnuniyet düzeyi, okul yöneticileri

\begin{abstract}
Organizations' performance is also effective in managing healthy crises that don't foresee as effective as in process of achieving their predefined goals. In this study, it was aimed to reveal opinions of teachers on satisfaction level of teachers from school principals on job performance. Case study was chosen as qualitative research design as research method. Research sample consisted of 20 primary school teachers, 10 female and 10 male in Ankara province during 2016-2017 academic year. Teachers' participation to research is based on volunteerism. The professional seniority of teachers varies between 3 and 20 years. While half of participants think that most school principals have managerial competencies, some participants think that they do not have competence. Participants agree that school principals announce the criteria that they use when evaluating performance of teachers. According to the view of majority of participants, there is a consensus that most school principals are sensitive to teachers' problems. Participants are in a consensus opinion that satisfaction with school principals affects business performance. It was determined that effect of teachers' satisfaction from school principals' on job performance did not differ according to the sex and occupational seniority of teachers. In particular, inservice training can be given to school principals in terms of enhancing teacher motivation and performance evaluation. Structural changes can be made in the appreciation, recognition and reward system in order to increase the satisfaction of the teachers in terms of appreciation, recognition and reward.
\end{abstract}

Keywords: Contentment level, school principals, work performance

\section{Giriş}

Çalışanların iş performansı örgütün performansını, örgütün verimliliğini, örgütsel amaçlara ulaşma sürecini etkiler. Örgütlerin performansı örgütün önceden belirlenen hedeflerini 
gerçekleştirme sürecinde etkili olduğu kadar öngörülemeyen krizleri sağliklı yönetme konusunda da etkilidir. Dünyada yaşanan ve yaşanması olası değişimlerin hızı ve kapsamı, izleme ve uyumun ötesinde, örgütlerin varlıklarını sürdürebilmelerinde; yaratıcılık, yönlendiricilik, etkileyicilik gibi liderlik süreçlerini içeren dirik bir yönetim anlayışını gerektirmektedir (Erçetin, 2000). Hayatın gerek bireysel gerekse örgütsel anlamda her boyutta hızlı yaşandığı günümüzde performansı yeterli olmayan örgütlerin piyasa koşullarında rekabet edebilmesi ve yaşamını sürdürebilmesi çok mümkün gözükmemektedir. Çalışanların iş performansını etkileyen birtakım faktörlere bakıldığında;

Motivasyon: Çalışanların performansını etkileyen en önemli faktörlerden biri motivasyondur. Motivasyonunun artmasında kritik faktör, örgütlerde etkililiğin sağlanmasıdır. Eğitim örgütlerinde ise eğitim kalitesini arttırmak, yönetim sistemini değiştirerek daha demokratik, kararlara katılımda öğretmenlerin de sorumluluğunun olduğu bir yönetim ş̧ekli öğretmen performansını artıracaktır. Eğitim öğretim ortamında fiziki koşulların iyileştirilmesi de öğretmen performansını artıran bir etmendir. Çalışma ortamının 1sısı, rengi, döşemesi rahatlatıcı ve ferah şekilde düzenlenip öğretmenin okulda ihtiyaç duyduğu malzemeler temin edilmelidir.

Ödüllendirme: Örgütlerde etkili bir ödül sisteminin varlığı da çalışan performansını artırır. Bu ödüller, maaş artışı ve ikramiye şeklinde olabilir. Buna paralel olarak mesleki açıdan çalışanları cezp edecek ödüller de önemlidir. Eğitim örgütlerinde okul yöneticilerinin etkili öğretimi ve güdüleyici uygulamaları nasıl yürürlüğe koydukları, performansın artması için, okulun kültürel yapısı ve değerlerinin motive edici şekilde değişimi önemlidir.

Çalı̧̧an Beklentileri ile Örgütün Hedeflerinin Uyumu: Çalışanın mesleki algıları, sağlanan olanaklar, örgütsel amaçları gerçekleştirebilmek için çalışanın ilgi, bilgi, yetenek ve birikimlerinin nasıl değerlendirildiği çalışan performansı açısından önemlidir.

Etkili Illetişim ve Güven: Örgüt ortamında çalışanlar ve yöneticiler arasında etkili iletişim ve işbirliğinin varlığı, güven ortamının sağlanmış olması çalışan performansı ve verimliliğine yansımaktadır. Okul yönetiminin öğretmenlerle iyi ilişkiler kurması da çalışan performansını arttıran bir faktördür (Helvacı, 2011). Yöneticiler ve çalışanların güven ortamında çalışmaları da oldukça önemlidir. Yönetici ve işgören ilişkilerinde güven duygusunun güven duygusunun oluşmasında, onaylayıcı örgüt ortamı, bilgi, disiplin etkenleri önemlidir (Küçükali, 2003).

Performans Değerlendirme Sistemi: Çalışan performansını ölçmek için yeterli, doğru ve kabul edilebilir bir performans değerlendirme sisteminin olması, örgütün performansını yükseltmeye olanak sağlayan sistemlerin geliştirilmesi, örgütsel adaletin oluşturulması motivasyonda kritik faktördür. Eğitim yöneticisi; tüm paydaşlarla iyi ilişkiler kurmak, beklentileri etkili şekilde yöneterek okul ortamında demokratik yönetimi sürdürmek zorundadır (Küçükali, 2003). Yöneticinin hakkaniyetle davranması önemlidir çünkü adalet duygusu sarsılan işgörenlerin işe bağl1lığ1 ve motivasyonu düşmektedir.

Memnuniyet Düzeyleri: Çalışan bireylerin iş yaşamında en önemli etkenlerden biri işlerinden memnuniyet düzeyleridir çünkü işinde memnuniyet düzeyi yüksek olan bireylerin verimliliği de artmaktadır. Çalışanların moralinin yüksek olması ve memnuniyet düzeylerinin yüksek olması verimliliği arttıran etmenlerdendir (Paul, 2012). Çalışan memnuniyetinin düşük olması ise çalışma ortamında birçok olumsuzluğu da beraberinde getirmektedir (Bağc1, 2014).

Çalışanların işten memnuniyetleri boyutunda en önemli faktörün ise yönetici memnuniyeti olduğu söylenebilir. Örgütlerde, işgören performansında en etkili faktör yöneticidir (Robertson,1996). Başarıll olmak isteyen yöneticilerin birbirini bütünleyen düşünce ve eylemleri içeren liderlik ve yöneticilik kavramları içselleştirmeleri gerekir (Erçetin, 2000). Okulların başarılı şekilde yönetilerek sağlıklı bir okul ortamı yaratılmasında okul müdürlerinin liderliği etkilidir (Avcı, 2015). Özetle denilebilir ki çalışanların işe yönelik yaklaşımlarının 
olumlu olması örgütün hedeflerinin gerçekleştirilmesi için özveriyle çalışmaları örgütün güçlenmesine katkı sağlamalarına neden olabilir (Bağcı, 2014).

Konuya ilişkin yapılan araştırmaların da öğretmenlerin iş performansının yöneticilerden memnuniyet düzeyinden etkilendiğini ortaya koymaktadır. Kentsel okul bölgelerindeki öğretmenlerin memnuniyet düzeylerini etkileyen faktörlerin ve okul yönetimine karş1 tutumlarını doğrudan etkileyen ayırt edici faktörlerin belirlenmesi amaciyla Lapert (2011) tarafından yapılan çalışmada öğretmenlerin çoğunluğunun idare tarafından desteklendiğini hissettikleri, cinsiyet, yaş, sınıf düzeyi faktörlerine göre ihtiyaçlarının farklılaştığı, bu nedenle yönetimin belirli sorunları bireysel olarak ele almaları gerektiği, maaş faktörünün ise memnuniyeti arttıran en etkili faktör olduğu sonucuna ulaşılmıştır.

Wambui Wangai (2015) tarafından Kenya'nın Nairobi ilçesindeki devlet okullarında öğretmenlerin iş doyumuna ilişkin liderlik davranışlarının araştırıldığı çalışmada öğretmenlerin iş doyumu ile yönlendirici, katılımcı, destekleyici ve başarı odaklı olmak üzere dört temel liderlik davranışının ilişkili olduğu, yöneticilerin \% 59.52'sinin başarı odaklı liderlik davranışı, \% 16.67'si destekleyici, \% 9,52'si destekleyici ve başarı odaklı,\% 7,34'ünün yönlendirici ve başarı odaklı, $\% 2.38$ 'i yönlendirici ve \% 2.38'lik katılımcı liderlik davranışları olduğu, öğretmenlerin \% 64.68'inin yüksek iş memnuniyetine sahip olduğu, \% 35,32'inin ise iş tatmini düşük olduğu sonuçlarına ulaşılmıştır. Ngimbudzi (2009) tarafından yapılan öğretmenlerin iş tatmini ile ilişkili faktörlerin incelendiği çalışmada öğretmenlerin sosyal fayda, yapılan işin anlamlılığı ve yönetimden görülen destek yönlerinden memnuniyet düzeylerinin yüksek olduğu sonucuna ulaşılmıştır. Bu çalışmada öğretmenlerin okul yöneticilerinden memnuniyet düzeylerinin iş performanslarına etkileri ile ilgili görüşlerini ortaya koymak amaçlanmıştır.

\section{Yöntem}

\section{Araştırma modeli}

$\mathrm{Bu}$ çalışmada nitel araştırma yöntemlerinden durum çalışması kullanılmıştır. Durum çalışması, bir duruma ilişkin etkenlerin bütüncül bir yaklaşımla araştırılması ile bunların ilgili durumu nasıl etkiledikleri ve ilgili durumdan nasıl etkilendikleri üzerine odaklanır (Yıldırım ve Şimşek, 2008). Bu çalışmada öğretmenlerin okul yöneticilerinden memnuniyet düzeylerinin iş performansları üzerindeki etkileri ile ilgili görüşlerini ortaya koymak amaçlandığı için nitel araştırma desenlerinden durum çalışması tercih edilmiştir, öğretmenlerin yöneticilerden memnuniyetlerinin performanslarını nasıl etkilediği ortaya konmuştur.

\section{Çalışma grubu}

Çalışma grubu 2016-2017 eğitim-öğretim y1lında Ankara ilinde ilkokullarda derse giren 10 kadın, 10 erkek toplam 20 sınıf öğretmeninden oluşmaktadır. Öğretmenlerin çalışmaya katılmaları gönüllük esasına dayanmaktadır. Öğretmenlerin mesleki kıdemleri ise 3 yıl ile 20 yıl arasında farklılık göstermektedir. Bu çalışmada çalışma grubuna dâhil olan öğretmenlere ulaşılabilir olmasından ve gönüllü olmalarından dolayı amaçlı örneklem kullanılmıştır. Araştırma verilerinin sunumunda katılımcılara verilen kodlardan yararlanılmış ve yorumlar bazı görüşlerden doğrudan alıntılar yapılarak desteklenmiştir. Çalışma grubunun özelliklerine ait bilgiler Tablo 1'de sunulmuştur.

Tablo 1.

Çalışma Grubunun Özellikleri

\begin{tabular}{llll}
\hline KS & Kod & Cinsiyet & K1dem \\
\hline 1 & K1 & Kadın & 16 \\
2 & K2 & Erkek & 15 \\
3 & K3 & Erkek & 10 \\
4 & K4 & Kadın & 11 \\
\hline
\end{tabular}




\begin{tabular}{llll}
\hline 5 & K5 & Kadın & 7 \\
6 & K6 & Erkek & 9 \\
7 & K7 & Kadın & 13 \\
8 & K8 & Kadın & 18 \\
9 & K9 & Erkek & 6 \\
10 & K10 & Erkek & 8 \\
11 & K11 & Erkek & 3 \\
12 & K12 & Kadın & 20 \\
13 & K13 & Kadın & 17 \\
14 & K14 & Erkek & 19 \\
15 & K15 & Kadın & 5 \\
16 & K16 & Kadın & 4 \\
17 & K17 & Erkek & 8 \\
18 & K18 & Erkek & 7 \\
19 & K19 & Kadın & 16 \\
20 & K20 & Erkek & 13 \\
\hline
\end{tabular}

\section{Verilerin toplanması}

Çalışmanın verileri yarı yapılandırılmış görüşme formuyla toplanmıştır. Bu yöntem seçenekli cevaplamayı sağlarken ilgili alanda derinlemesine araştırmayı birleştirir (Büyüköztürk ve diğerleri, 2010). Araştırmada kullanılan görüşme soruları araştırmacı tarafindan ilgili alan yazının taraması yapılarak hazırlanmış ve uzman görüşü alınarak kapsam geçerliliği gözden geçirilmiş sorulardan oluşturulmuştur. Öğretmenler "K1, K2 ... K20" olarak kodlanmıştır. Mülakat uzunlukları sirasıyla 20, 19, 21, 23, 25, 25, 24, 22, 26, 22, 21, 23, 25, 24, 21, 20, 22, 23, 22 ve 20 dakikadır. Araştırmada öğretmenlere yöneltilen sorular şunlardır: Görev yaptı̆̆ınız okulda, okul yöneticinizden memnuniyetinizi olumlu etkileyen özellikleri nelerdir? Olumsuz etkileyen özellikleri nelerdir? Göreviniz esnasında yöneticinizden memnuniyet durumunuzun iş performansınızı nasıl etkilemektedir?

\section{Verilerin analizi}

$\mathrm{Bu}$ araştırmada görüşme yoluyla elde edilen veriler, betimsel analiz yöntemiyle incelenmiş ve yorumlanmıştır. Veriler dört aşamada analiz edilmiştir: 1. Verilerin kodlanması, 2. Kodlanan verilerin temalarının belirlenmesi, 3. Kodların ve temaların düzenlenmesi, 4. Bulguların tanımlanması ve yorumlanması (Yıldırım ve Şimşek, 2008, s. 228). Analiz sürecinde öncelikle, görüşme kayıtları ve yazılı formlar deşifre edilip çözümlemeler yapılmıştır. Bununla birlikte katılımcıların görüş ve düşüncelerini yansıtacak doğrudan alıntılara da yer verilmiştir. Bunlar araştırma verilerinin geçerlik ve güvenirliğini artıracak uygulamalar olarak kabul edilebilir.

\section{Bulgular}

\section{Öğretmenlerin görüşlerine göre öğretmenlerin yöneticilerden memnuniyeti}

Katılımcıların görüşleri doğrultusunda bu tema: yöneticilerin liderlik davranışlarından memnuniyet, yöneticilerin performans değerlendirme yaklaşımından memnuniyet, yöneticilerin problemlere yaklaşımından memnuniyet olmak üzere üç farklı kategoride incelenmiştir.

\section{Yöneticilerin liderlik davranışlarından memnuniyet}

Katılımcıların yarısından çoğu yöneticilerin liderlik davranışlarını sergileme açısından yeterli olduğunu düşünürken bazı katılımcılar ise yeterliliğe sahip olmadığını düşünmektedirler. Katılımcılardan K3 "Yöneticimiz istek ve ihtiyaçlarımızı dikkate alır ve elinden geldiği kadar çözümüne yönelik olarak hareket eder." derken K18 "Okul müdürümüzün yönetici olduğunu çoğu zaman hatırlamakta güçlük çekiyorum adeta, etkisiz davrandı̆̆ durumlar oluyor." 
ifadelerini kullanarak durumu özetlemişlerdir. Yöneticilerin liderlik davranışlarından memnuniyete yönelik frekans ve yüzde dağglımı Tablo 2'de sunulmuştur.

Tablo 2.

Yöneticilerin Liderlik Davranışlarından Memnuniyete Yönelik Frekans ve Yüzde Dağılımı

Yönetici yeterliliklerine sahip olma

f 12

Yöneticilerin insan ilişkilerine önem vermesi 14

Yaratıcı ve yenilikçi fikirleri teşvik etmesi $\quad 12$

Öğretmenlerin görüşlerini dikkate alma durumu

12

\begin{tabular}{ll}
\hline & $\%$ \\
\hline 12 & 60 \\
14 & 70 \\
12 & 60 \\
12 & 60 \\
\hline
\end{tabular}

Katılımcılar yöneticilerin insan ilişkilerine önem verdiğini ifade etmişlerdir.

"Müdürümüz okulumuza gelen velilere olsun diğer kişilere olsun gerçekten çok nazik davranır, insanların memnun ayrılması için gerekenleri yapar (K11)."

"Hastalandığımda veya acil bir durum oluştuğunda izine ihtiyacım olduğunda herhangi bir sorun çıkarmaz, insanız istenmedik durumlar yaşayabiliyoruz, işe gelecek durumda olamayabiliyoruz. Bu anlamda hiç sıkıntı yaşatmaz (K1).”

Yöneticilerin performans değerlendirme yaklaşımından memnuniyet

Katılımcılar yöneticilerin öğretmenleri değerlendirirken kullandığı kriterleri duyurmaları konusunda hemfikirdir.

Duyurular konusunda müdürümüz hassastır, sadece değerlendirme kriterlerini değil gerekli olan tüm duyuruları zamanında yapar (K12)."

"Kriterlerin açıkça duyurulması hoşuma gidiyor, hangi noktalarda değerlendirildiğimi biliyorum (K19)."

Yöneticilerin performans değerlendirme yaklaşımından memnuniyete ilişkin frekans ve yüzde dağılımlarına ilişsin bilgiler Tablo 3’te sunulmuştur.

Tablo 3.

Yöneticilerin Performans Değerlendirme Yaklaşımından Memnuniyete İlişkin Frekans ve Yüzde Dağılımları

\begin{tabular}{|c|c|c|}
\hline & $\mathrm{f}$ & $\%$ \\
\hline Yöneticilerin öğretmenleri değerlendirirken kullandığ1 & 20 & 100 \\
\hline kriterleri öğretmenlere duyurması & & \\
\hline Yöneticilerin $\quad$ ögretmenlerin & 16 & 80 \\
\hline yükseltmek için gerekli önlemleri alması & & \\
\hline $\begin{array}{l}\text { Yöneticiler, performansı iyi olan öğretmeni aylıkla } \\
\text { ödül, takdir, teșekkür vs ile ödüllendirmesi }\end{array}$ & 8 & 40 \\
\hline $\begin{array}{l}\text { Yöneticiler, performansı iyi olan öğretmeni öğretmenler } \\
\text { kurulu toplantılarında, törenlerde vb. duyurarak takdir } \\
\text { etmesi }\end{array}$ & 10 & 50 \\
\hline
\end{tabular}

"Müdürümüz her zaman performansımıza yönelik bir düşüş yaşandığında sebebine dair bizimle bire birde konuşur, dikkate alınmak değer verilmek bile daha fazla özen göstermem için yeterli oluyor çoğu zaman (K5).” 
"Performansımızın en iyi yükselme yöntemi aslında maaşla ödüllendirme ama her zaman bu mümkün olmasa da, ufak tefek ödül yöntemleri kullanıyor (K17).”

Katılımcılar performansı iyi olan öğretmenlerin ödüllendirilmesi konusunda sıkıntı olduğu görüşündedirler.

"Müdürümüz performansı iyi olan öğretmenleri ilçeye bildirdiğini ifade ediyor, ama hiçbir arkadaşımıza da kolay kolay başarı belgesi falan gelmiyor, anlamadım (K6)."

"Müdürümüz genellikle toplantılarda performansı iyi olan arkadaşlara teşekkür ediyor, bazen atladığı da oluyor, özellikle atlamasa da gücüne gidiyor insanın, çünkü işyerinde insan kimseden olmasa da müdüründen yaptığı işlere dair güzel sözler duymak istiyor, motive edici oluyor (K9)."

Yöneticilerin problemlere yaklaşımından memnuniyet

Katılımcıların yarısından çoğu yöneticilerin öğretmenlerin problemlerine duyarlı olduğu konusunda görüş birliği içerisindedir. Yöneticilerin Problemlere Yaklaşımından Memnuniyete İlişkin Frekans ve Yüzde Dağılımlarına ilişkin bilgiler Tablo 4'te sunulmuştur.

Tablo 4.

Yöneticilerin Problemlere Yaklaşımından Memnuniyete İlişkin Frekans ve Yüzde Dağılımları

\begin{tabular}{ccccc}
\hline & & & $\mathrm{f}$ & $\%$ \\
\hline $\begin{array}{c}\text { Yöneticilerin } \\
\text { durumu öğretmenlerin }\end{array}$ & problemlerine & duyarlılık & 14 & 70 \\
$\begin{array}{c}\text { Karş1laşılan problemlerde } \\
\text { destekleyici katkısı }\end{array}$ & yöneticilerin & çözüme & 13 & 65 \\
\hline
\end{tabular}

"Bir süre babamın hastalığı ile ilgili problemlerim olmuştu, çok hassas davrandı gerçekten (K2)."

"Malzeme eksiğine dair, eğitim öğretime dair olan problemleri hılı bir şekilde çözüme ulaştırıyor gerçekten (K4)."

"Müdürümüzün çözemiyorum dediği bir durum varsa biliyorum ki elinde değil, o güveni verdi gerçekten (K8).”

"Bizim çabamızı gördüğünde katkısı daha fazla oluyor, ama her şeyi ondan beklersek tavrı değişiyor tabi ki (K3).”

"Müdürümüz biraz sert görünüşlü, çekindim ilk başta ama bir veli ile sıkıntı yaşamıştım, destek oldu gerçekten (K7)."

\section{Öğretmenlerin yöneticilerden memnuniyetinin iş performansına etkisi}

Katılımcılar yöneticilerden memnuniyetin iş performansını etkilediği konusunda görüş birliği içerisindedir. Katılımcı ifadelerinden bazıları ise şöyledir.

"Müdürüm beni takdir ettiğinde motivasyonum, azmim artıyor, daha iyi ders anlatıyorum sanki (K10)."

"Başarılı bir proje yapmıştım, müdür beni bir projede çalışan başka bir arkadaşımla birlikte çok istediğim bir etkinliğe gönderdi ödül olarak, çok mutlu oldum, başka bir proje başlattık, kesinlikle etkili oluyor (K13)." 
"Yöneticiden memnun olmak ve olmamak arasında performans anlamında çok fark oluyor. Eski okulumda annem ölmüştü, ölüm izni kullandım, dönüşte daha okula gelir gelmez müdür benden ölüm belgesi istedi, o kadar incindim ki, başka bir okula tayin istedim. Şu an çalıştığım okuldaki müdürüm insan ilişkilerinde son derece hassas, kimseyi kırmıyor, o bize insancıl ve iyi niyetli yaklaştığı için benim de motivasyonum artıyor ve canla başla çalışıyorum (K14)."

"Çocuklarımız nasıl bizden güzel bir söz duyunca motive oluyorsa biz de yöneticimizden takdir bekliyoruz, yöneticimizden memnun olunca okulun havası bile değişiyor (K15)."

"Çok etkiliyor gerçekten, okul ortamı bile değişiyor (K16)."

"Yöneticiden memnun olmayınca insan tam kapasite çalışamıyor zaten, içinden gelmiyor, memnun olunca elinden geleni yapmaya gayret ediyor (K20)."

"Müdürümün yapmak istediğim projeleri desteklemesi projenin başarısına katkıda bulunuyor. Çok istediğim bir çalışmaya itiraz ettiğinde ise bir açıklama bekliyorum haliyle, mantıklı bir açıklaması olursa modum düşmüyor, elimden geleni yapıyorum (K9)."

"Müdürümle zaman zaman çatışmalarımız oluyor, öğrencilerle ilgili konularda, özel hayatlarımızla ilgili bir sıkıntı yaşadığımızda mutlaka destek oluyor, artısı fazla diyelim. Yönetici konumunda olduğu için mutlaka ki yaptığımız işleri beğenmesi bizi etkiliyor (K7)."

"Yaptığımız güzel işleri öğretmenler kurulunda, bazen törenlerde, bazen de velilerin de olduğu ortamlarda takdir ediyor, işime karşı motivasyonum tabi ki etkileniyor, yepyeni projeler üretiyorum (K6)."

Katılımcıların görüşleri cinsiyetlerine ve mesleki kıdemlerine göre değerlendirildiğinde öğretmenlerin yöneticilerden memnuniyet durumunun iş performansına etkisinin öğretmenlerin cinsiyetine ve mesleki kıdemlerine göre bir farklılık göstermediği sonucuna ulaşılmıştır. Öğretmenlerin cinsiyeti ve kıdemi fark etmeksizin yöneticilerden takdir gören öğretmenlerin performansının arttığı söylenebilir.

\section{Tartışma, Sonuç ve Öneriler}

Çalışmada öğretmenlerin okul yöneticilerinden memnuniyet düzeylerinin iş performansları üzerindeki etkileri ile ilgili görüşlerini ortaya koymak amaçlanmıştır. Çalışmadan elde edilen sonuçlar ele alındığında;

Çalışmada katılımcıların yarısından çoğu yöneticilerin yönetici yeterliliklerine sahip olduğunu düşünürken bazı katılımcılar ise yeterliliğe sahip olmadığını düşünmektedirler. Katılımcılar yöneticilerin insan ilişkilerine önem verdiğini, yöneticilerin öğretmenleri değerlendirirken kullandığı kriterleri duyurduklarını, yöneticilerden memnuniyetin iş performansını etkilediğini ifade etmişlerdir.

Ayrıca yöneticilerin öğretmenlerin performanslarını yükseltmek için gereken önlemleri almasının da öğretmenlerin performanslarını etkilediğini ifade etmişlerdir. Katılımcıların yarısı ise yöneticilerin performansı iyi olan öğretmeni aylıkla ödül, takdir, teşekkür ile ödüllendirmesi, performansı iyi olan öğretmeni öğretmenler kurulu toplantılarında, törenlerde. duyurarak takdir etmesinin performanslarını etkilediğini belirtmişlerdir. Katılımcıların yarısından çoğu yöneticilerin öğretmenlerin problemlerine duyarlı olduğu konusunda görüş birliği içerisindedir. Nitekim Bağcı (2014) çalışmasında, çalışanların huzurlu bir çalışma ortamında yalnızca görev 
tanımlarında bulunan faaliyetleri değil, gönüllü faaliyetleri de yerine getirmekten geri kalmayacaklarını ifade etmiştir.

Katılımcıların yöneticilerden memnuniyet durumunun iş performansına etkisine dair görüşlerinin öğretmenlerin cinsiyetine ve mesleki kıdemlerine göre bir farklılık göstermediği söylenebilir. Nitekim, Dorozynska (2016) tarafından yapılan çalışmada okul ortamı özellikleri ele alındığında öğretmen-öğrenci ilişkileri ve okul yönetiminin desteği, öğretmenlerin iş tatmini ile pozitif yönde ilişkiliyken, stres ve disipline ilişkin konuların ve sosyal desteğin eksikliği ile negatif yönde ilişkili olduğu sonucuna ulaşılmıştır.

Araştırma sonucunda öğretmenlerin okul yöneticilerinden memnuniyet düzeylerinin iş performansları üzerindeki etkili olduğu söylenebilir. Araştırma bulgularına dayanılarak şu önerilerde bulunulabilir:

- Özellikle öğretmen motivasyonunu arttırma ve performans değerlendirme konularında yöneticilere hizmet içi eğitim verilebilir.

- Öğretmenlerin takdir, tanıma ve ödüllendirme konularında memnuniyetini arttırmak adına takdir, tanıma, ödüllendirme sisteminde yapısal değişiklikler yapılabilir.

\section{Kaynaklar}

Avc1, A. (2015). Öğretmen algılarına göre okul müdürlerinin liderlik stilleri. Hasan Ali Yücel Ĕ̈itim Fakültesi Dergisi, 12-2(24), 161-189.

Bağcı, Z. (2014). Çalışanların iş doyumunun görev ve bağlamsal performansları üzerindeki etkisi. Yönetim ve Ekonomi Araşttrmaları Dergisi, 24, 58-72 Doi: http://dx.doi.org /10.11611/JMER534 58

Büyüköztürk, Ş., K1lı̧̧ Çakmak, E., Akgün, Ö.E., Karadeniz, Ş. ve Demirel, F. (2010). Bilimsel araştırma yöntemleri. Ankara: Pegem-A Yayınları.

Dorozynska, A. (2016). Teacher Job Satisfaction in Primary Schools: The relation to work environment. (International Master in Educational Research). Department of Education and Special Education, Göteborgs Universitet.

Erçetin, Ş. Ş. (2000). Örgüt sarmalında vizyon. Ankara: Nobel Yayın Dă̆ıtım

Halpert, M. A. (2011). Factors affecting teacher satisfaction in an urban school district. (A dissertation presented in partial fulfillment of the requirements for the degree doctor of education). Arizona State University, Arizona.

Helvac1, M. A. ve Aydoğan, İ. (2011). Etkili okul ve etkili okul müdürüne ilişkin öğretmen görüşleri. Uş̧ak Üniversitesi Sosyal Bilimler Dergisi, 4(2), 41-60

Küçükali, R. (2003). Bazı yöneticilik davranışları açısından öğretmenlerin yöneticileri algılama düzeyi. Atatürk Üniversitesi Sosyal Bilimler Enstitüsü Dergisi, 2(1-2), 197-214

Ngimbudzi, F. W. (2009). Job Satisfaction among Secondary School Teachers in Tanzania: The Case of Njombe District. (Master's thesis in education). Department of Educational Sciences, Institute of Educational Leadership, University of Jyvaskyla

Paul, T. (2012). The impact of age and education on the level of satisfaction and motivation among employees. The IUP Journal of Management Research, 11(1), 29-37.

Robertson, R. F. (1996). Develop a performance-focused organization. Hdrocarbon Processing Dec., 75(12), 81-86

Wambui Wangai, N. (2015). Principals' Leadership Behaviours and Teachers' Job Satisfaction in Public Secondary Schools, Nairobi County, Kenya. (A thesis submitted in partial fulfillment of the requirements for the award of the degree of doctor of philosophy). The Department of Educational Psychology, School of Education of Kenyatta University.

Yıldırım, A. ve Şimşek, H. (2008). Sosyal bilimlerde nitel araştırma yöntemleri (6. Baskı). Ankara: Seçkin Yayınevi. 


\section{Extended Abstract}

\section{Introduction}

Work performance of employees affects organization performance, organizational productivity, and organizational goals. Organizations' performance is also effective in managing healthy crises that do not foresee as effective as in the process of achieving their predefined goals. It is unlikely that organizations whose performance is inadequate today cannot compete and survive in market conditions, as life is an individual, organizational sense, and fast in every dimension. When a number of factors affecting the work performance of employees are examined; motivation, rewarding, employee expectation and adaptation of organization goals, effective communication and trust, performance evaluation system, satisfaction levels. Motivation: One of the most important factors affecting the performance of employees is motivation. The critical factor in increasing motivation and morale is ensuring effectiveness in organizations.

Rewarding: The presence of an effective reward system in organizations also increases employee performance. These prizes can be in the form of additional salaries and bonuses. Parallel to the increase in salaries, the incentives obtained from the professional perspective are also important.

Adaptation of Employee Expectations and Organizational Goals: Perceptions of the worker's occupation, the possibilities provided based on these perceptions and expectations, how the employee's interest, knowledge, skills and experience are assessed in order to achieve organizational goals is important for employee performance.

Effective Communication and Trust: The existence of effective communication and collaboration between employees and managers in the organizational environment and the provision of trust environment reflects on employee performance and productivity.

Performance Evaluation System: Having an adequate, accurate and acceptable performance evaluation system to measure employee performance, developing systems that can improve organizational performance, and establishing organizational justice are critical factors in motivation.

Satisfaction Levels: One of the most important factors in the working life of working individuals is the level of satisfaction with their work because the productivity of the individuals with high levels of job satisfaction is also increasing.

It can be said that the most important factor in the aspect of employees' satisfaction from work is manager satisfaction. In organizations, it is known that the most effective factor in occupational performance is the manager (Robertson, 1996). Leadership and management include non-identical, but complementary, thoughts and actions, which are perceived as a necessity by managers who want to succeed in contemporary organizations (Erçetin, 2000). In this study, it was aimed to reveal the opinions of the teachers on the satisfaction level of teachers from school principals on the job performance.

\section{Method}

In the study, case study was chosen as qualitative research design as research method. The research sample consisted of 20 primary school teachers, 10 female and 10 male in Ankara province during 2016-2017 academic year. Teachers' participation to research is based on volunteerism. The professional seniority of teachers varies between 3 and 20 years. In this study, the data were collected by semi-structured interview technique. Semi-structured interview technique is used because of providing flexibility. The interview questions used in the research were prepared by the researcher by searching the related field and the opinion of the expert was taken and the validity of the scope was established from the questions that were examined. In this study, data obtained through interviews were examined and interpreted by means of descriptive analysis. However, direct citation has also been included to reflect original ideas and thoughts. These can be considered as applications that will increase the validity and reliability of research data. 


\section{Results and Discussion}

According to the view of the participants, satisfaction with the leadership behavior of school principals theme has been examined in three different categories: Satisfaction with school principals' leadership behaviors, satisfaction with school principals' viewpoint to performance evaluation, satisfaction with school principals' viewpoint on problems. While half of the participants think that most school principals have managerial competencies, some participants think that they do not have competence. Participants agree that school principals announce the criteria that they use when evaluating performance of teachers. According to the view of the majority of participants, there is a consensus that most school principals are sensitive to teachers' problems. Participants are in a consensus opinion that satisfaction with the school principals affects business performance. It was determined that the effect of teachers' satisfaction from school principals' on job performance did not differ according to the sex and occupational seniority of teachers.

Participants are in a consensus opinion that satisfaction with the school principals affects business performance. As a matter of fact, during the research of Bağc1 (2014), when employees find a peaceful work environment, they will not only refrain from fulfilling their voluntary activities that contribute to the social and psychological environment beyond their expectations. In particular, in-service training can be given to school principals in terms of enhancing teacher motivation and performance evaluation. Structural changes can be made in the appreciation, recognition and reward system in order to increase the satisfaction of the teachers in terms of appreciation, recognition and reward. 